Publisher homepage: www.universepg.com, ISSN: 2663-7804 (Online) \& 2663-7790 (Print)

https://doi.org/10.34104/ajeit.020.01060112

Australian Journal of Engineering and Innovative

Technology

Journal homepage: www.universepg.com/journal/ajeit

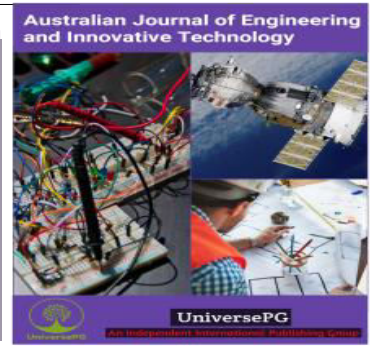

\title{
Comparative Studies of Electrical Resistance in Woven and Non-Woven Jute Fabrics at Different Input Voltage
}

\section{Sharmin Akter ${ }^{1}$, Tahnin Bintay Kamal ${ }^{2}$, Ashraful Alam², Mahmuda Khatun ${ }^{3}$, Manika Rani Debnath ${ }^{4}$, and Md. Zobaidul Hossen ${ }^{5}$}

${ }^{1}$ Textile Physics Division, Bangladesh Jute Research Institute, Dhaka, Bangladesh; ${ }^{2}$ Mechanical Processing Division, Bangladesh Jute Research Institute, Dhaka, Bangladesh; ${ }^{3}$ Product Development Division, Bangladesh Jute Research Institute, Dhaka, Bangladesh; ${ }^{4}$ Agronomy Division, Bangladesh Jute Research Institute, Dhaka, Bangladesh and ${ }^{5}$ Microbiology and Biochemistry Department, Bangladesh Jute Research Institute, Dhaka, Bangladesh.

*Corresponding author: zobaidulgeb@gmail.com (Department of Microbiology and Biochemistry, Bangladesh Jute Research Institute, Dhaka-1207, Bangladesh).

\begin{abstract}
The use of jute fabrics is showing an increasing trend in textile, building and automobile sectors. Electrical properties such as conductivity, resistance, di-electric constant, insulation, etc. are the essential factor for consideration for using jute fabrics in these sectors. For this reason, a study was carried out to find out the changes in electrical properties of woven and nonwoven jute fabrics at different input voltage. The electrical resistance of jute fabrics was measured by a digital impedance meter. Effects of input voltage, gauge length, and type of fabrics on electrical resistance were studied and analyzed. Experimental results indicated that the electrical resistance of woven and needle punched nonwoven jute fabrics decreased with the increase of input voltage and increased with the increase in gauge length. The highest value of electrical resistance in woven jute fabrics was $394 \mathrm{Mohm} / \mathrm{cm}$ at $2 \mathrm{~cm}$ gauge length and $60 \mathrm{~V}$ of the input voltage. In nonwoven jute fabrics, the maximum electrical resistance was $257 \mathrm{M}$ ohm/cm which was obtained at $2 \mathrm{~cm}$ gauge length and $60 \mathrm{~V}$ of electrical resistance. Woven jute fabric showed a higher value of resistance than nonwoven jute fabric for different voltages. It was also observed that the electrical resistance varied with the type of fabrics used in this study.
\end{abstract}

Keywords: Woven, Non-woven, Voltage, Gauge length, Jute-fabric, Needle punched, and Electrical resistance.

\section{INTRODUCTION:}

Jute is a common natural fibre which is produced on a wide scale in the Indian sub-continent, especially Bangladesh and has a nominal effect on the environment because of its biodegradable properties (Vilaseca et al., 2007). Many types of natural and plastic fibres are available in the world. Every natural fibre has strong properties (Cantero et al., 2003). As a result, jute fibre

UniversePG I www.universepg.com also has many advantages which are high mechanical and electrical properties, low cost, low weight, good thermal properties, enhanced energy recovery, biodegradability and so on (Bullions et al., 2004; Mohanty et al., 2000). Jute is the cheapest lingo- cellulosic long vegetable- based fiber and is abundantly available in Bangladesh (Akter et al., 2020). It is traditionally used for making hessian clothes, ropes, gunny and shopping bags, floor mats, etc (Rahman et al., 2008). 
Jute is a bast fibre of Tiliaceae family. Bangladesh is second jute producing country. Plant of jute takes nearly 120 days for growing to a height of $10-15$ feet. The jute fibre comes from the stem and ribbon of the plant by separating through retting from the plant (Khan and Khan, 2015). Jute fibre has strong physical and chemical properties. Jute contains $61-65 \%$ of cellulose; 13.6-20.40\% of hemi-cellulose; $12-13 \%$ lignin (Hanamanagouda et al., 2016); $0.2 \%$ of pectin; $0.5 \%$ of waxes (Komuraiah et al., 2014); 12.6\% of moisture content (Hanamanagouda et al., 2016). The properties depend on the atmosphere and temperature of the region. Density and fibre length of jute fibres are 1.3-1.45 $\mathrm{g} / \mathrm{cm}^{3}$ and 0.8-6 mm (Shubhra et al., 2011). Tensile strength of jute fibre is 393-773 MPa (Narayan et al., 2017) and Young's Modulus is 13-26.5 GPa (Kabir et al., 2012). Different electrical properties like conductivity, resistance, resistivity power, insulating parameter, etc. are important in many textile applications such as apparel, gloves and jackets for electrical work, building insulation, automobiles, aircraft and industrial process equipment and floor covering where high voltage machines are kept. Different textile materials are used as insulator for long time. Usually the conductive wire is wrapped with cotton or silk yarns for insulation (Sengupta and Sengupta, 2012).

Synthetic materials are widely used as insulator rather than natural textile material for low cost. Use of jute fabric as insulator will minimize the heat that is generated during the current flow through electrical wire in high voltage. The amount of heat which is generated during current flow through jute fabrics in high voltage is an essential matter. The electrical resistance of an object is a measure of the problem to pass an electric current through that conductor. It determines the amount of current passing through the object for a given potential difference across the object accordance with Ohm's law ( $\mathrm{I}=\mathrm{V} / \mathrm{R})$, where $\mathrm{I}=$ the current in ampere, $\mathrm{V}=$ the potential difference across the object in volts and $\mathrm{R}=$ the resistance in ohm. Different textile materials like cotton, silk yarns are usually used as insulator. But the use of textile materials fabricated from natural fibre has been reduced with the extensive use of synthetic polymers. It has reduced the total cost of insulation. On the other hand, the natural fibre jute has gained more attention because of its availability, low cost and also for eco-friendly uses. There is enough possibility of using jute fabrics as insulator.

Two types of jute fabrics are used in this study: woven and needle punched non-woven jute fabrics for measuring the electrical properties. Weaving is the very common method of making fabrics and it has been used since ages to make different fabrics (Gupta et al., 2012). However, the fact is that threads or yarn goes through a process called weaving to be converted into a fabric. In weaving, two or more threads or yarns run in vertical to each other to make a pattern called warp and weft. Threads or yarns run up and down the length of the fabric in warp direction while weft threads run alongside the fabric and this weaving of the two threads creates a woven pattern which is called fabric. At first the weft threads go over the warp thread and then they go under the next warp thread (Khan et al., 2016). Needle punching is a method of bonding fibrous fleeces mechanically. In needle punching method, the fibers are mechanically twisted to produce a fabric by reciprocating hooked needles (felting needles) through a moving bat of fibers in a needle loom (Maity et al., 2012). Many research works have been done on jute based needle-punched nonwoven which has been focused on the following broad areas of applications: (a) in geo-textile, (b) in agro textile, (c) use as reinforced material in composites, (d) reuse the waste of production in carpet industry (Maity et al., 2012).

In the literature, there is very few information regarding the insulating properties of jute fabrics. Keeping this in mind, a study has been made to measure and analyze the electrical resistance of different jute fabrics in order to understand the effects of different input voltage or different gauge length or different types of fabrics. It will help to use jute fabrics in technical textiles where electrical resistance property is required during use.

\section{MATERIALS AND METHODS:}

\section{Materials}

Woven and non-woven jute fabrics were used to measure electrical properties (Fig 1 and Fig 2). Woven jute fabric was collected from the Technology Wing of Bangladesh Jute Research Institute, Dhaka. The fabric is called plain jute fabric as it has the same ends and 
picks per inch and the value is 13 . The GSM value of woven jute fabric is $305 \mathrm{gm} / \mathrm{m}^{2}$. $10 \mathrm{lbs} / \mathrm{spy}$ yarn was used in both warp and weft direction. Non-woven jute fabric was collected from Janata Jute Mills Ltd., Narsingdi, Bangladesh. It was produced through needle punched process. Raw jute fibre was softened by using JBO oil and then processed in a breaker card.

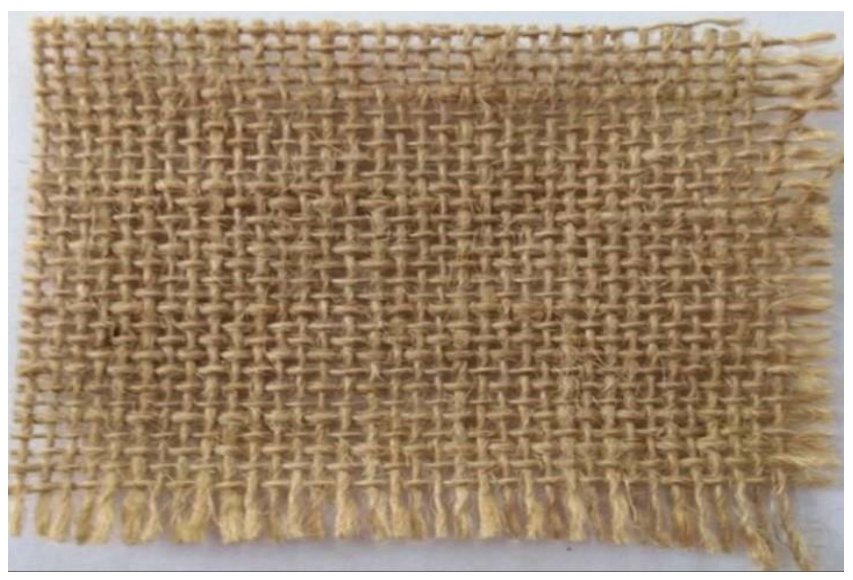

Fig 1: Woven jute fabric.

\section{Methods}

The experiment was performed by using Digital Impedance Meter. The Fig 3 shows the digital impedance meter. This meter is a digital format of LRC circuit. Samples are placed at fixed terminal of the meter and the expected results are shown on the screen. The resistance was measured by changing input voltage at first and collected respective results from the screen. Results for different gauge length of two fabrics were done by following the same procedure. At first woven jute fabric sample of $1.0 \mathrm{~cm}$ gauge length was placed on respective terminal. The sample was in series with a known resistance $10 \mathrm{Mohm}$ and was connected to a DC power supply. The voltage was changed from 60 to 100 volts and corresponding current through the sample was measured.

The current was taken after 10 seconds to measure resistance. These steps were repeated for woven nonwoven jute fabrics of $1.0,1.5$ and $2.0 \mathrm{~cm}$ of gauge length. Experimental readings were taken to draw a V-I characteristics curve. The V-I characteristics of each slope were determined. This experiment was performed at room temperature $\left(30^{\circ} \mathrm{C}\right)$.
After that the breaker card sliver was fed to Dilo non-woven plant covering a roller and a clearer card to make needle-punched non-woven jute fabric. To complete the process a camel back cross-lapper and a needle loom were used. The GSM value of non-woven jute fabric was $400 \mathrm{gm} / \mathrm{m}^{2}$.

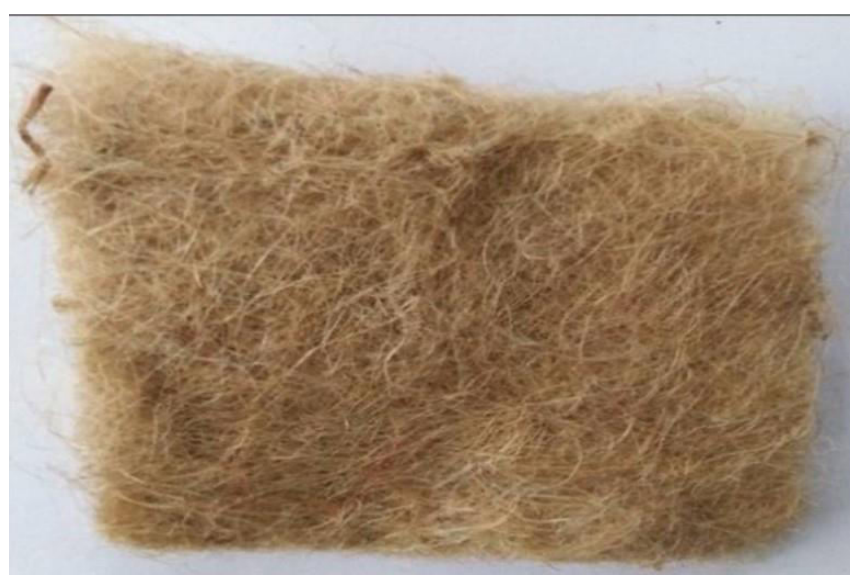

Fig 2: Non-woven jute fabric.

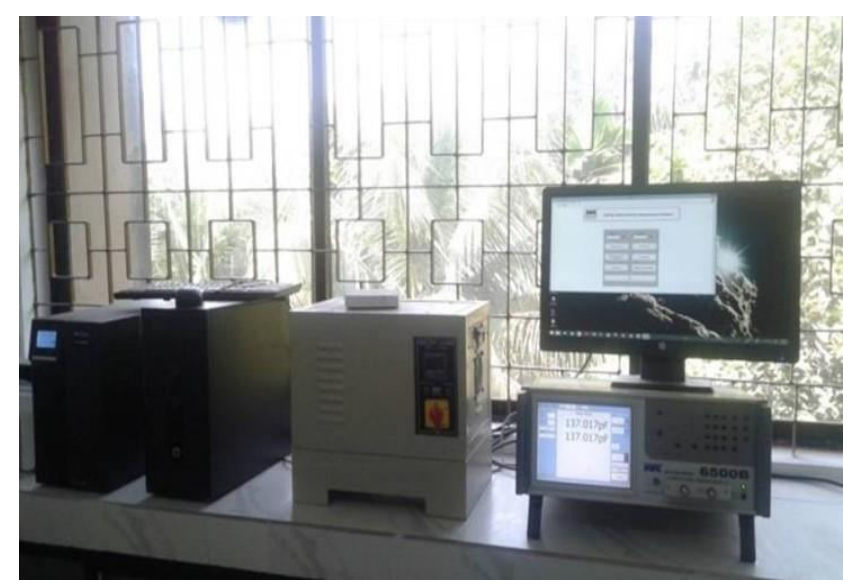

Fig 3: The Digital Impedance Meter.

\section{RESULTS AND DISCUSSION:}

Electrical resistance was measured for both woven and non-woven jute fabrics at different input voltages for different gauge length. Fig 4 shows the electrical resistance for the input voltage of 60 volts for different gauge length. From Fig 4(a), it was observed that at 60 volts of input voltage, woven jute fabric had high resistivity than non-woven jute fabric. From Fig 4(b) and 4(c), it was also observed that with the increase of gauge length of jute fabric, electrical resistance incre- 
ased for both woven and non-woven jute fabrics. The highest value of electrical resistance was found for 2 $\mathrm{cm}$ of gauge length for both woven and non-woven jute fabrics. The difference of resistance between woven and non-woven jute fabrics increased with the higher value of gauge length.

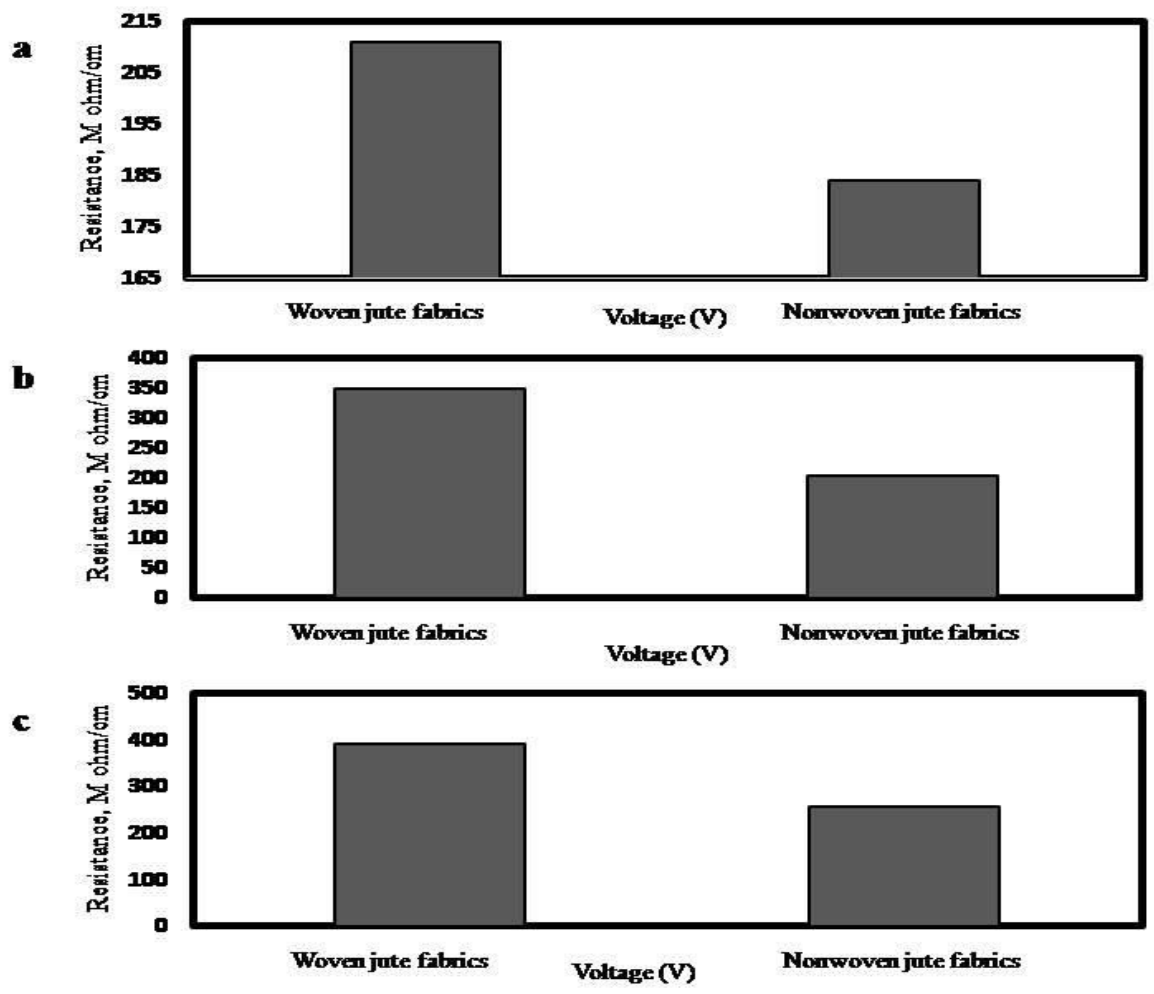

Fig 4: Electrical resistance at 60 volts for different gauge length (A, at gauge length $1 \mathrm{~cm}$; $\mathrm{B}$, at gauge length 1.5 $\mathrm{cm}$; and $\mathrm{C}$, at gauge length $2 \mathrm{~cm}$ ).
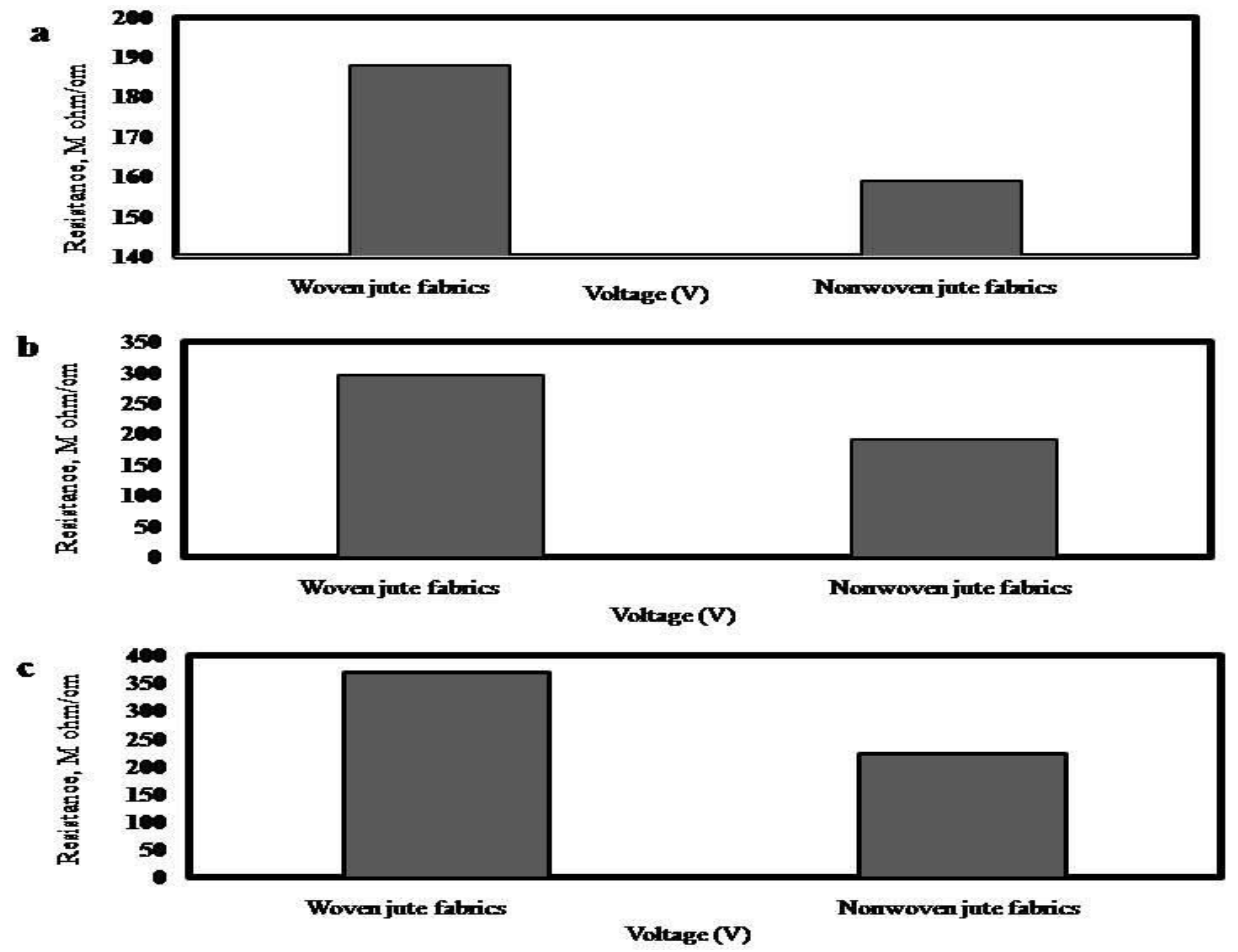

Fig 5: Electrical resistance at 80 volts for different gauge length (A, at gauge length $1 \mathrm{~cm}$; $\mathrm{B}$, at gauge length $1.5 \mathrm{~cm}$; and $\mathrm{C}$, at gauge length $2 \mathrm{~cm}$ ). 
For changing the gauge length from 1 to $1.5 \mathrm{~cm}$, the rate of increase in resistance for woven jute fabric was 65.88 $\%$ and for non-woven jute fabric was $15.41 \%$. And for the change of 1.5 to $2 \mathrm{~cm}$ of gauge length, the rates of increase were 12.57 and $25.42 \%$ for woven and nonwoven jute fabrics, respectively. At 60 volts, a significant trend of increasing electrical resistance was observed for both types of fabrics with higher gauge length.

From Fig 5(a), 5(b) and 5(c), it was observed that at 80 volts of input voltage, the highest value of resistance was determined for $2 \mathrm{~cm}$ of gauge length for both types of fabrics. At 80 volts, the difference of resistance between woven and non-woven jute fabrics increased with the higher value of gauge length. This means, the higher difference was found for $2 \mathrm{~cm}$ of gauge length. For changing the gauge length from 1 to $1.5 \mathrm{~cm}$, the rate of increase in resistance for woven jute fabric was $60.97 \%$ and for non-woven jute fabric was $21.38 \%$. And for the change of 1.5 to $2 \mathrm{~cm}$ of gauge length, the rates of increase were 24.91 and $16.32 \%$ for woven and non-woven jute fabrics, respectively.

Fig 6 shows the relation between electrical resistance and gauge length at input voltage of 100 volts. From Fig 6(a), 6(b) and 6(c), it was observed that for changing the gauge length from 1 to $1.5 \mathrm{~cm}$, the rate of increase in resistance for woven jute fabric was $60.22 \%$ and for non-woven jute fabric was $45.90 \%$. And for the change of 1.5 to $2 \mathrm{~cm}$ of gauge length, the rates of increase were 23.76 and $9.55 \%$ for woven and non-woven jute fabrics, respectively.

The change of resistance for different gauge lengths in different input voltages has been shown in Fig 7. Specific resistance increased with the increase in gauge length and it happened for both woven and nonwoven jute fabrics. From Fig 7(a), 7(b) and 7(c), it can be concluded that insulating property of fabric increased with the increase in length between two measuring jaws. The rate of change was not same for different gauge length.

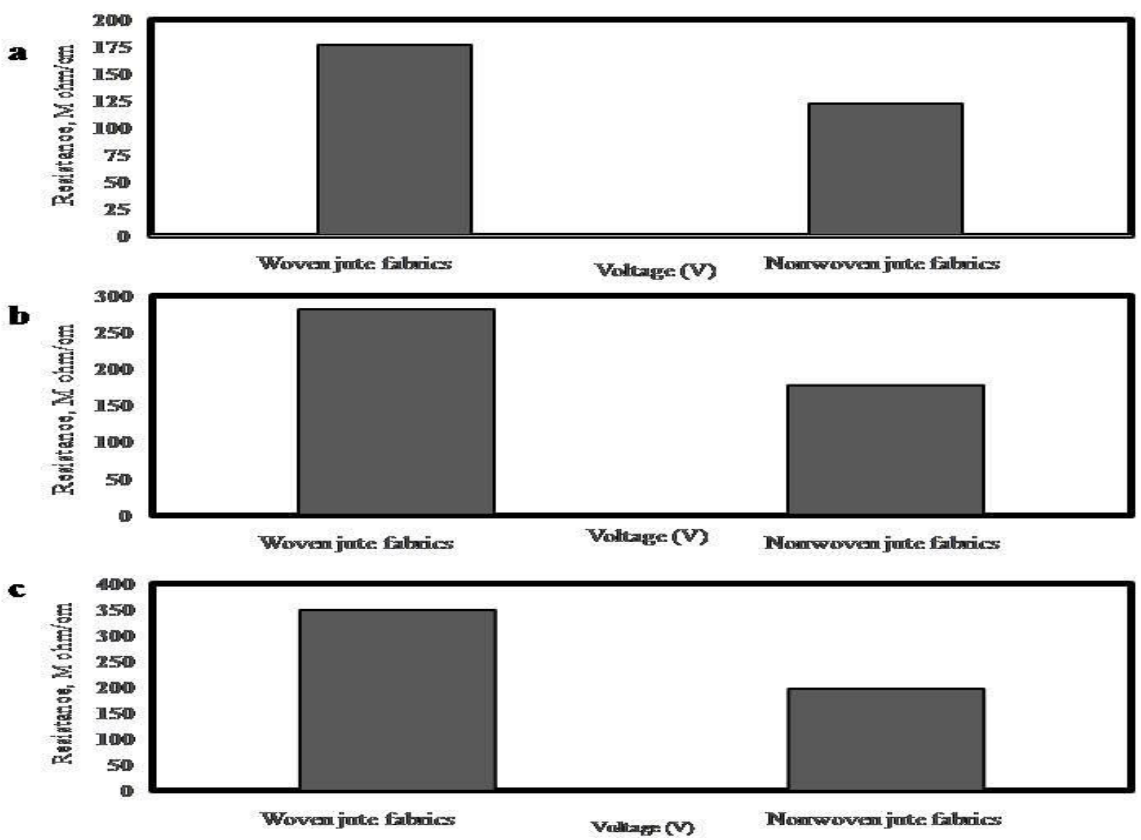

Fig 6: Electrical resistance at 100 volts for different gauge length $(\mathrm{A}$, at gauge length $1 \mathrm{~cm}$; $\mathrm{B}$, at gauge length 1.5 $\mathrm{cm}$; and $\mathrm{C}$, at gauge length $2 \mathrm{~cm}$ ).

The change rate was higher for $2 \mathrm{~cm}$ gauge length and lower for $1 \mathrm{~cm}$. Therefore the non woven jute fabrics have shown different values at $1.5 \mathrm{~cm}$ of gauge length, whereas the woven jute fabric had nearest the same value as for other gauge length. Results showed that the resistance was highest for woven jute fabric and lowest UniversePG I www.universepg.com for non-woven jute fabric. Woven fabric was designed with two sets of tight and twisted yarns which were arranged along the length and width in a systemic way. Once current was flowing through the length of the material of fabric, then the width portion was not directly taking part within the conductivity. 


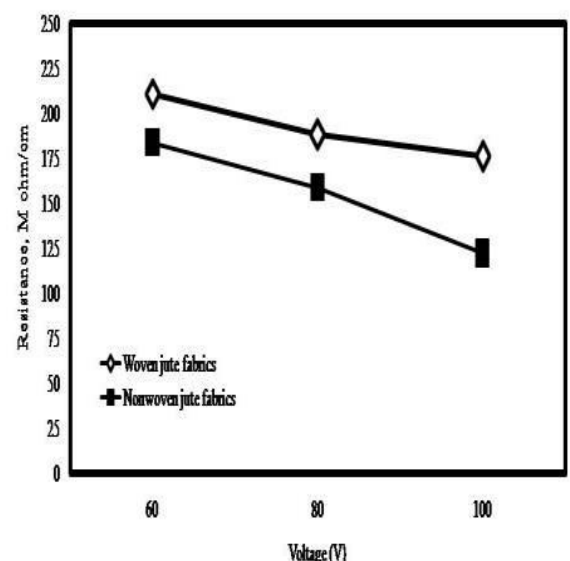

Fig 7(a): Comparative electrical resistance at different voltages in woven and nonwoven jute fabrics at gauge length $1 \mathrm{~cm}$.

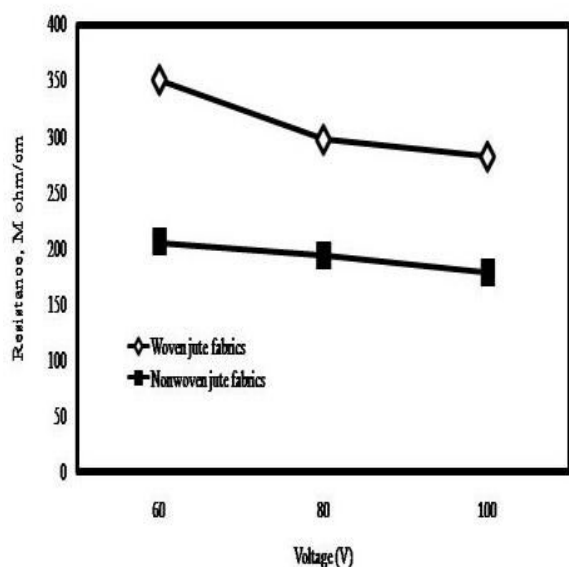

Fig 7(b): Comparative electrical resistance at different voltages in woven and nonwoven jute fabrics at gauge length $1.5 \mathrm{~cm}$.

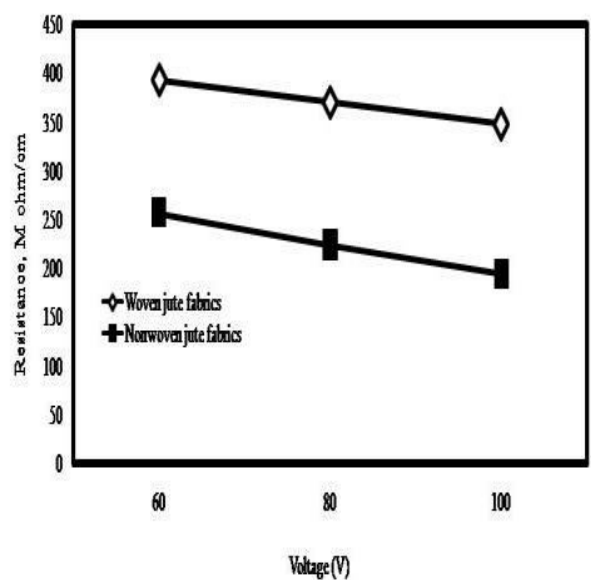

Fig 7(c): Comparative electrical resistance at different voltages in woven and nonwoven jute fabrics at gauge length $2 \mathrm{~cm}$.
For example if measurement was done in warp direction, the current was not directly passing through the weft direction. On the other hand, needle punched nonwoven fabric structure showed that all the fibres were arranged and interlinked in such a way that the width of fabric was not equally same. At higher voltages, the interfacial polarization was become less active with the rapidly changing electric field. This resulted to a decrease or constant value in resistivity. The void area between the fibres that created lower fabric density compared to woven fabric did not play much because of the inter-fibre contacts which acted as a whole in conduction of electricity. Probably this was the main reason for lower resistance of nonwoven fabric.

\section{CONCLUSION:}

In a word, the electrical resistance of woven and nonwoven jute fabrics decreases with the increase of input voltage. For non-conducting material resistance remain constant with the increase of voltage as current also increases with the increase of voltage. Resistance values increased with an increase in the gauge length for both jute fabrics. The non-woven jute fabric has lower resistance power than the woven jute fabric and the reason is the current is not passing proportionately through the fabrics and hence resistance decreases. There is always a direction which is not passing current through it in woven jute fabric. Breakdown of insulation is usually resulted for the significant fall at high voltages. It signifies that if we want to use nonwoven and woven both jute fabrics as electrical purposes, we should take special care for using higher voltages. The resistance increases with the increase of gauge length of fabrics. It means that, the gauge length is more important matter of consideration for using woven and non-woven jute fabrics as insulator. Overall, the woven jute fabrics exhibited higher resistivity properties than the needle punched non woven jute fabrics.

\section{ACKNOWLEDGEMENT:}

We are greatly acknowledged to Bangladesh Jute Research Institute (BJRI), Dhaka, Bangladesh, where this research work has been conducted. The authors would like to convey their heartiest thanks to all officers and lab assistants in BJRI for their continuous support and help to make this work a successful.

\section{CONFLICTS OF INTEREST:}

The author (s) declared no potential conflicts of the interest with respect to the research, authorship and/or publication of this article.

\section{REFERENCES:}

1. Akter S, Kamal T B, Khatun M, Alam M M, Hossen M Z and Karim R (2020). Influence of Potential Differential Voltage on Electric Resistance of Needle Punched Non-Woven 
Jute Fabrics. Australian Journal of Engineering and Innovative Technology, 2(1), 1-6. https://doi.org/10.34104/ajeit.020.0106

2. Bullions T A, Gillespie R A, Price-O'Brien J and Loos A C. (2004). The effect of maleic anhydride modified polypropylene on the mechanical properties of feather fiber, kraft pulp, polypropylene composites. J App Polym Sci; 92: 3771-3783.

3. Cantero G, Arbelaiz A, Llano-Ponte R and Mondragon I. (2003). Effects of fiber treatment on wettability and mechanical behavior of flax/polypropylene composites. Compos Sci Technol; 63: 1247-1254. https://doi.org/10.1016/S0266-3538(03)00094-0

4. Gupta, Manoj \& Srivastava, Ravindra \& Bisaria, Himanshu. (2015). Potential of Jute Fibre Reinforced Polymer Composites: A review. International Journal of Fiber and Textile Research. 5: 30-38.

5. Hanamanagouda, B S, Keerthi Gowda, Easwara L and Ramachandran, Velmurugan. (2016). Mechanical Properties of Raw Jute Polyester Composite. International Journal of Fiber and Textile Research. 6: 20-24.

https://www.researchgate.net/publication/309732 $\underline{363}$

6. Kabir M.M., Wang H., Lau K.T., Cardona F. (2012). Compos. Part- B. 43: 2883-2892.

7. Khan, J. A., and Khan, M. A. (2015). The use of jute fibers as reinforcements in composites. Biofiber Reinforcements in Composite Materials, 3-34.

8. Khan, G. M. A., Terano, M., Gafur, M. A., and Alam, M. S. (2016). Studies on the mechanical properties of woven jute fabric reinforced poly (1-lactic acid) composites. Journal of King Saud University-Engineering Sciences, 28(1), 6974. https://doi.org/10.1016/j.jksues.2013.12.002
9. Komuraiah A., Shyam N.K. and Durga B.P. (2014). Mech. Compos. Mater. 50.

10. Mohanty AK, Misra M and Hinrichsen G. (2000). Biofibers, biodegradable polymer and biocomposites: An overview. Macromol Mater Eng; 276: 1-24.

11. Mwaikambo, L. Y., and Ansell, M. P. (2002). Chemical modification of hemp, sisal, jute, and kapok fibers by alkalization. Journal of Applied Polymer Science, 84(12), 2222-2234. https://doi.org/10.1002/app.10460

12. Narayan Nayak, Dr. Reddappa H. N, Ganesh R Kalagi, Vijendra Bhat (2017). Electrical Insulating Properties of Natural Fibre Reinforced Polymer Composites; A Review, International Journal of Engineering Research and Technology (IJERT), 6, 8.

13. Rahman M.R., Huque M.M., Islam M.N. and Hasan M. (2008). Comp. Part- A. 39, 17-39.

14. Sengupta S., and Sengupta, A. (2012). Electrical resistance of jute fabrics. Indian Journal of Fibre Textile Research, 37(1), 55-59. https://doi.org/10.1080/00405000.2012.699940

15. Shubhra, Q. T., Alam, A., and Quaiyyum, M. (2011). Mechanical properties of poly-propylene composites. Journal of Thermo- plastic Composite Materials, 26(3), 362-391. https://doi.org/10.1177/0892705711428659

16. Subhankar Maity ,Kunal Singha , Debi Prasad Gon , Palash Paul and Mrinal Singha (2012). A Review on Jute Nonwovens: Manufacturing, Properties and Applications, International J. of Textile Science, 1(5), pp. 36-43. https://doi.org/10.5923/j.textile.20120105.02

17. Vilaseca, F., Mendez, J. A., Pelach, A., Llop, M., Canigueral, N. and Girones, J. (2007). Composite Materials Derived from Biodegradable Starch Polymer and Jute Strands, Process Biochemistry, 42: 329-334. https://doi.org/10.1016/j.procbio.2006.09.004

Citation: Akter S, Kamal TB, Alam A, Khatun M, Debnath MR and Hossen MZ. (2020). Comparative studies of electrical resistance in woven and non-woven jute fabrics at different input voltage, Aust. J. Eng. Innov. Technol., 2(6), 106-112. https://doi.org/10.34104/ajeit.020.01060112 @) 